\title{
Long-term efficacy and safety of otilonium bromide in the management of irritable bowel syndrome: a literature review
}

This article was published in the following Dove Press journal:

Clinical and Experimental Gastroenterology

7 April 2014

Number of times this article has been viewed

\author{
John K Triantafillidis \\ George Malgarinos \\ Inflammatory Bowel Disease Unit, \\ IASO General Hospital, Athens, \\ Greece
}

Correspondence: John K Triantafillidis Inflammatory Bowel Disease Unit, IASO General Hospital, 264 Mesogeion Avenue, Maroussi I5I23, Greece

Email jktrian@gmail.com

\begin{abstract}
Irritable bowel syndrome (IBS) is a very common functional gastrointestinal disorder characterized by abdominal pain or discomfort and altered bowel habits. The disease affects a large part of the world population. The clinical course is mostly characterized by a cyclic recurrence of symptoms. Therefore, IBS patients should receive, as an initial therapeutic approach, a short course of treatment, and long-term treatment should be reserved for those patients with recurrent symptoms. The available clinical trials show that significant improvement of the symptoms over placebo could be achieved with various drugs, although this improvement is frequently time dependent and with high relapse rates after the cessation of the treatment. In a proportion of patients, clinically obvious relapse could appear long after stopping the treatment. Some of the available pharmacologic agents, including otilonium bromide (OB), are able to significantly prolong the time to the appearance of relapse, compared with placebo. As a consequence, some authors suggest that a cyclic treatment could be of benefit. Antispasmodic drugs have been used for many years in an effort to control the symptoms of IBS. OB is a poorly absorbed spasmolytic drug, exerting significantly greater control of the symptoms of IBS compared with placebo. Recent data suggest that the drug could effectively be used for the long-term management of patients with IBS. The aim of this review is to provide the reader with an evidence-based overview of the efficacy and tolerability of $\mathrm{OB}$ in the long-term management of IBS patients, based on the results of the clinical trials published so far.
\end{abstract}

Keywords: irritable bowel syndrome, IBS, treatment, otilonium bromide

\section{Introduction}

Irritable bowel syndrome (IBS) is a very common functional gastrointestinal disorder characterized by abdominal pain or discomfort and altered bowel habits. It affects about $12 \%-20 \%$ of the world population, having a significant negative impact on patients' quality of life. The exact etiopathogenesis of this syndrome remains obscure, although significant progress on biochemical, psychosocial, and physiologic mechanisms has recently been achieved. ${ }^{1,2}$

During the last years, various antispasmodic drugs for the treatment of IBS have been evaluated in a number of clinical studies. Otilonium bromide $(\mathrm{OB})$ is a poorly absorbed antispasmodic drug, which has significantly greater efficacy compared with placebo in controlling the symptoms of patients with IBS. ${ }^{3}$ The drug has been approved for the relief of symptoms of patients with IBS in most countries of the world, including Europe, Australia, and South and North America.

The aim of this review is to provide the reader with an overview of the efficacy and tolerability of $\mathrm{OB}$ in the long-term management of patients with IBS, based on 
the results of the available clinical trials. Meta-analyses were not included in this review. However, the only one available so far $^{4}$ does not include the recently published and most important Otilonium Bromide in Irritable Bowel Syndrome (OBIS) study. ${ }^{5}$

\section{Natural course of IBS}

The natural history of IBS has not been fully elucidated. It is generally characterized by a recurrence of the symptoms, the severity of which changes over time. In most cases, the clinical course is characterized by the presence of mild to moderate symptoms, appearing sequentially. After many years, the majority of patients will still have symptoms that could change to another subtype of IBS or overlap with dyspeptic symptoms. ${ }^{6}$

IBS seems to be a heterogeneous clinical entity. ${ }^{7,8}$ Older studies have revealed that after a follow-up period ranging from 1 year to 32 years, $73 \%$ of patients still experienced symptoms. ${ }^{9-11}$ In a systematic review, Guilera et al ${ }^{12}$ concluded that the prevalence of IBS subtypes differs according to the geographical location, population studies, and criteria employed to define IBS. Mearin et $\mathrm{al}^{7}$ followed up a large cohort of IBS patients. They found that after 3 months, twothirds of patients reported the same IBS subtype, but only half of them fell into the very same clinical pattern. In a subsequent study, the same group of investigators described that after 1-year follow-up, half of the patients and their physicians considered the IBS to have had some improvement. ${ }^{13}$ A systematic review concluded that after a median follow-up of 2 years, $30 \%-50 \%$ of patients with IBS had unchanged symptom severity, $2 \%-18 \%$ developed worse IBS, and the rest either improved or saw a disappearance of symptoms. ${ }^{14}$

The available data suggest that the pattern of IBS symptoms is cyclical. More than half of IBS patients are still symptomatic after up to 10 years, and clinical symptoms are present or disappear in days to weeks. The benefit from the treatment may extend beyond 4 weeks, but relapse rates are high (around 40\% when stopping treatment after 3 months), although relapse is not always immediate after the cessation of the treatment. The benefit of treatment could be clinically obvious for more than 1 year, although the relapse rate after treatment withdrawal, following long-term (1-year) treatment, is still quite high $(40 \%){ }^{6}$

\section{OB in the treatment of IBS} General considerations of the use of $O B$

Patients with IBS could be conservatively managed by either short or long-term treatment. Some patients require only "single-shot" treatment, while others need treatment for a longer period. Certainly, patients with continuous symptoms require long-term treatment.

The suggestion for short-term treatment is based on the following: 1) a significant number of IBS patients improve over time and thus they do not need further treatment, 2) about $50 \%$ of patients do not relapse during the followup period, 3) most relapses do not occur immediately after stopping treatment, and 4) certain treatments might have long-lasting positive effects. On the contrary, the suggestion for long-term treatment of IBS patients is based on the following: 1) more than $50 \%$ of patients continue to have symptoms for months or years, 2) the favorable results of treatment continue for a long period of time, 3) relapse of symptoms after the cessation of treatment could appear in more than $50 \%$ of the treated patients, and 4) the positive results of treatment might appear several days or weeks after the initiation of treatment. ${ }^{15}$

The intensity, frequency, and specificity of the symptoms in a given patient could decisively influence the therapeutic strategy applied. Sometimes, the symptoms may be of mild, moderate, or severe intensity, requiring only reassurance in some cases, an intervention in others, and multimodal intervention in a minority of them. If the symptoms are continuous, occasional, or intermittent, then continuous, limited, or on-demand treatment could be applied, respectively. It must be emphasized that the drug of first choice is selected on the basis of the dominant symptom. ${ }^{15}$ If the treatment is unsuccessful, the drug can be changed; otherwise, it can be suspended after a limited course. If a relapse occurs, treatment should be resumed with the same drug. If, however, the patient remains in remission, he/she might not receive unnecessary treatment. Most experts agree that long-term treatment should be reserved for patients who experience recurrent symptoms, and that a cyclic treatment should be applied in all patients, being in accordance with the natural behavior of the disease. ${ }^{15}$

\section{Chemistry and structural formula of $O B$}

The chemical description of OB is diethylmethyl(2-[4-\{2octyloxybenzamido benzoyloxy]-ethyl)ammonium bromide. The molecular formula of the drug is $\mathrm{C}_{29} \mathrm{H}_{43} \mathrm{BrN}_{2} \mathrm{O}_{4}$ and the molecular weight 563.6. The long aliphatic chain favors the binding of the drug to the cell membrane of the target tissue, thus increasing the duration of its pharmacologic effects. The positively charged nitrogen atom of $\mathrm{OB}$ is responsible for the scant systemic absorption and the poor penetration in the central nervous system. 


\section{Pharmacologic properties of $O B$}

After oral administration, OB has poor systemic absorption thanks to physicochemical characteristics, and remains in the gastrointestinal tract acting locally. ${ }^{16}$ In animal models, the plasma levels of the drug were 1,000 times lower than in the gastrointestinal tract. ${ }^{17}$ Pharmacokinetic studies in humans have revealed that the drug was almost entirely eliminated by feces..$^{18}$ The small absorbed fraction (3\%) is rapidly eliminated from the circulation through the biliary tract. Therefore, $\mathrm{OB}$ is subject to enterohepatic recirculation. ${ }^{19}$ The drug does not cross the blood-brain barrier. Orally administered ${ }^{14} \mathrm{C}$-otilonium bromide is able to effectively penetrate into the large intestine walls, a recognized target for drugs oriented toward IBS therapy. ${ }^{17} \mathrm{OB}$ is considered to be a paracellularly transported drug whose absorption is favored by bile salts. ${ }^{20}$

An interesting point is how the drug gains access to the enteric neuromuscular apparatus to achieve its effects. In vitro studies demonstrated that $\mathrm{OB}$ is accumulated in its principal sites of action, namely the inner layer of the large bowel circular muscle and the submucosa. ${ }^{21}$ The colonic receptor binding profile of $\mathrm{OB}$ gives a molecular explanation for the spasmolytic effect of the drug. A combination of antimuscarinic and $\mathrm{Ca} 2+$ channel blocker properties best accounts for the action of $\mathrm{OB}^{22}$

\section{Mechanism of the action of $O B$}

The drug exerts its action through several mechanisms determined by the presence of several receptors and chemical mediators. The drug is able to act on calcium channels, cholinergic pathways, and neurokines receptors.

\section{Intestinal motility (calcium channels)}

The drug restores physiologic motility and enhances pain threshold to various intestinal stimuli by extra- and intracellular mechanisms. At the extracellular level, OB blocks the $\mathrm{Ca}^{++}$fluxes in the intestinal smooth muscle cells through $\mathrm{Ca}^{++}$ channels, acting as an antagonist of either voltage-operated $\mathrm{Ca}^{++}$channels or selected receptors. At the intracellular level, the drug inhibits $\mathrm{Ca}^{++}$release from sarcoplasmic reticulum.

\section{Antisecretory potential (cholinergic pathways)}

Acetylcholine is one of the extracellular transmitters involved in the regulation of intestinal fluid secretion. When acetylcholine binds to $M_{3}$ receptors, a calcium wave generated by mobilization of calcium from intracellular stores propagates from the basis of the crypt to its apex. This stimulates an increase in chloride in the epithelium, followed by the secretion of fluid into the intestinal lumen. OB, as an anticholinergic agent, inhibits muscarinic $\mathrm{M}_{3}$ receptor-coupled calcium signals and acetylcholine-induced calcium mobilization at the level of the colonic epithelium, thus exhibiting an antisecretory potential in IBS patients with diarrhea. ${ }^{23}$

\section{Tachykinin receptors}

Tachykinins play a major role in visceral nociception. In several animal studies, $\mathrm{NK}_{2}$ receptor antagonists were shown to decrease the nociceptive response to rectal and abdominal distension. OB antagonizes tachykinin receptors on the intestinal smooth muscle cells and afferent nervous terminations, thus modulating the development of intestinal hyperalgesia.

As a consequence, OB, by causing inhibition of L-/T-type calcium channels, muscarinic, and tachykininergic responses concurrently, could effectively exert its pharmacologic properties. $^{24}$

\section{Physiologic effects of $O B$}

OB has many physiologic effects on the bowel smooth muscles, such as spontaneous and triggered contractions and visceral hypersensitivity.

\section{Effect on bowel motility and smooth muscles}

OB inhibits basal and stimulated gastrointestinal motility in response to contracting agents of different natures, either chemical or physical. A combination of $\mathrm{Ca}^{++}$ channel blocking properties and mild antimuscarinic effects explains the pharmacologic action of the drug. ${ }^{25,26}$ In the micrometer range of concentrations, $\mathrm{OB}$ acts as a muscarinic and tachykinin $\mathrm{NK}_{2}$ receptor antagonist and as a calcium channel blocker. The latter property is likely to account for its ability to suppress contraction initiated by the tachykinin $\mathrm{NK}_{1}$ receptor agonist. Therefore, multiple mechanisms of action account for the ability of OB to reduce stimulated motility of intestinal smooth muscle. ${ }^{27}$ $\mathrm{OB}$ antagonizes the internalization of the $\mathrm{NK}_{2}$ receptor in the human colon. ${ }^{28}$ Functional studies showed a significant increase in maximal contraction induced by $\mathrm{NK}_{1 \mathrm{r}}$ agonist, and chronic exposition to $\mathrm{OB}$ significantly affects the $\mathrm{NK}_{\mathrm{r}}$ ! $\mathrm{SP} / \mathrm{NO}$ circuit. ${ }^{29}$ Gallego et al ${ }^{30}$ showed that OB strongly inhibited the main patterns of human sigmoid motility in vitro by blocking calcium influx through L-type calcium channels on smooth muscle cells. OB inhibits the spontaneous and triggered muscular contractions via inhibition 
of muscular action potentials carried by L-type calcium current. $^{31}$

\section{Reduction of visceral hypersensitivity}

Visceral hypersensitivity seems to play a significant role in the development of symptoms in IBS patients. OB reduces visceral hypersensitivity by enhancing sensory thresholds to rectosigmoid distension. Czimmer et al ${ }^{32}$ investigated patients with IBS by synectics visceral stimulator barostat, using rapid phasic distension. The pressure threshold of pain was significantly higher 1 week after treatment. The pressure and volume thresholds for maximum tolerable volume were significantly increased by 1 -week OB treatment.

\section{Clinical pharmacology and efficacy of $O B$}

$\mathrm{OB}$ is used as an antispasmodic for treating spastic painful conditions of the intestinal tract, including IBS. It is also effective in reducing intestinal spasm during endoscopy. A reduction in the hypermotility induced by several stimuli has been observed both in healthy subjects and in patients with IBS. ${ }^{18}$ In IBS patients, OB significantly reduced the magnitude and duration of the impaired gastrocolonic response to food. OB is able to antagonize delayed and greater motility in IBS patients. ${ }^{33}$ The effect of the drug on the intensity of pain could be obvious after the first day of administration with standard therapeutic dose, increasing gradually thereafter.

The efficacy of OB in patients with IBS has been documented in a large number of clinical trials, in the majority of which the standard therapeutic dose of $40 \mathrm{mg}$ three times a day was used. The first study, which demonstrated the efficacy of $\mathrm{OB}$ in patients with IBS, diarrhea variant, is that of Battaglia et al. ${ }^{34}$ The authors conducted a double-blind, placebo-controlled, randomized, 15-week study in patients with IBS on a 0-3 score scale with the following efficacy parameters: symptoms (abdominal pain intensity, distension, bowel habits, pain frequency, diarrhea/constipation severity, means of evacuation during days of evacuation, days without evacuation, mucus in stool, consistency of stool, sensation of incomplete evacuation, difficulty in evacuation), investigator objective signs (tenderness of sigmoid colon, pain evocation), quality of life (on a visual analog scale, ranked 0-10), and global assessment of efficacy by the investigators. After a 2-week placebo run-in, 325 patients were randomly assigned to receive either OB 40 $\mathrm{mg}$ three times daily or placebo for 15 weeks. The reduction in the number of abdominal pain episodes was significantly higher in OB patients $(55.3 \%)$ than in those taking placebo (39.9\%), as was the severity of abdominal distension $(42.0 \%$ versus [vs] $30.2 \% ; P<0.05)$. The visual analog scale revealed a significant improvement $(P<0.05)$ in patients taking OB. The investigators' global positive assessment was in favor of $\mathrm{OB}$ (65.2\%) compared with placebo (49.6\%) $(P<0.01)$.

Glende et al ${ }^{35}$ conducted a double-blind, placebocontrolled, parallel-group study in 378 IBS patients who were treated for 15 weeks with $40 \mathrm{mg}$ OB or placebo three times daily. The rate of response to treatment within 2-4 months (primary endpoint) was significantly higher in the OB group (36.9\%) than in the placebo group $(22.5 \%$; $P=0.007)$. Also, the total monthly and weekly responses to the single endpoints were significantly more frequent in the OB group than in the placebo group. Considering the three major endpoints (pain intensity, pain frequency, and presence of meteorism and distension), OB showed significantly higher proportions of responders compared with placebo. Finally, OB exerts a relevant antisecretory effect on human colonic crypts, offering additional benefits in patients with diarrhea.

Baldi et $\mathrm{al}^{36}$ described a significant improvement of abdominal pain and boating with OB vs placebo. Seventy-two patients with IBD complaining mainly of abdominal pain were studied in a double-blind trial. OB in a dose of $40 \mathrm{mg}$ three times daily was compared with placebo. OB significantly reduced pain and bloating, and significantly increased the pain threshold throughout treatment. Sigmoid motility during distension was significantly reduced after OB, but it did not change after placebo.

A study performed in 117 Asian IBS patients meeting Rome II criteria showed that OB exhibited similar efficacy compared with mebeverine in reducing abdominal pain, flatulence, and abdominal bloating. ${ }^{37}$

Compared with pinaverium bromide, OB seems to be more effective in reducing the number of pain attacks. ${ }^{38} \mathrm{Also}$, the combination of $\mathrm{OB}$ with diazepam probably increases the beneficial effect by reducing the level of anxiety. ${ }^{39}$ Finally, the meta-analysis of Lesbros-Pantoflickova et $\mathrm{al}^{4}$ showed that improvement of IBS symptoms with all antispasmodic drugs was maintained only for OB but on the basis of only two studies.

Table 1 shows the results of the main studies related to the use of OB in IBS patients.

\section{Long-term studies on the efficacy of $O B$ in IBS patients}

The OBIS study 5 confirmed the efficacy of OB during and following treatment in patients with IBS. In this study, 356 patients with IBS meeting Rome II criteria participated 


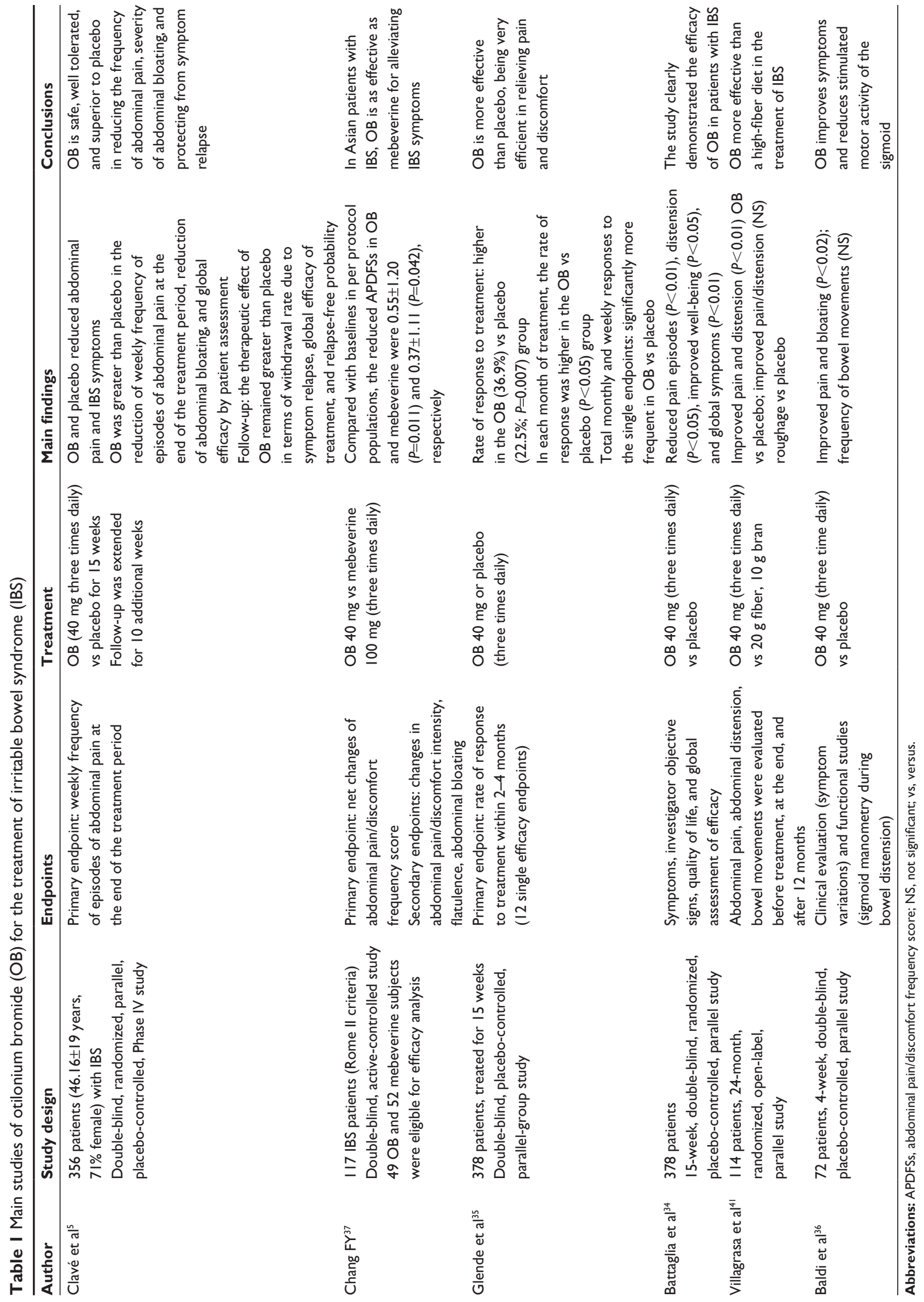


in a double-blind, randomized, parallel, placebo-controlled, Phase IV study. OB (40 mg three times daily) or placebo was administered for 15 weeks. Patients who completed the 15 -week period were subsequently allocated to a 10 -week follow-up without receiving any drug therapy. The follow-up was extended for 10 more weeks. A total of 179 patients were assigned to 15 weeks of treatment with $\mathrm{OB}$ and 177 to placebo. The results showed that although both $\mathrm{OB}$ and placebo reduced abdominal pain and IBS symptoms, the effect of OB was significantly greater in the reduction of weekly frequency of episodes of abdominal pain at the end of the treatment period (primary endpoint $-0.90 \pm 0.88 \mathrm{vs}-0.65 \pm 0.91, P=0.03$ ), reduction of abdominal bloating $(-1.2 \pm 1.2$ vs $-0.9 \pm 1.1$, $P=0.02)$ and global efficacy by patient assessment (1.3 $\pm 1.1 \mathrm{vs}$ $1.0 \pm 1.1, P=0.047$ ). Intensity of abdominal pain, proportion of patient responders, safety, and quality of life scores were similarly affected by OB and placebo. During the follow-up period, the therapeutic efficacy of OB remained greater than placebo in terms of withdrawal rate due to symptom relapse (10\% vs $27 \%, P=0.009)$, global efficacy of treatment, and relapse-free probability $(P=0.038)$.

This study showed that $O B$, apart from being superior to placebo in reducing both abdominal pain and bloating, was able to protect against the appearance of symptom relapse in IBS, as the results obtained with $\mathrm{OB}$ at the end of the treatment period also persisted during the follow-up. It is possible that the chemical characteristics of $\mathrm{OB}$ and its affinity for colonic smooth muscle may be the decisive factors influencing the prolonged benefit of the drug, which was not observed with other spasmolytic drugs. Obviously, this effect is of major importance in the clinical management of patients with IBS, especially if the intermittent kind of therapy has been chosen. Finally, the OBIS study showed that relapse rates in IBS patients varied considerably. This fact supports the suggestion of treating patients with intermittent or cyclic mode. ${ }^{16,40}$ However, the optimal long-treatment strategy has not yet been elucitated (Table 1).

In another study, which included 114 patients with IBS, OB in the suggested dose ( $40 \mathrm{mg}$ three times daily, $\mathrm{n}=61$ ) was more effective than a diet that included daily $20 \mathrm{~g}$ of fiber and $10 \mathrm{~g}$ of bran $(\mathrm{n}=53)$. OB resulted in an improvement in pain and abdominal distension towards pretreatment significantly higher compared with the results of the diet alone at the end of 24 months of follow-up $(P<0.01) .{ }^{41}$

\section{Adverse effects - safety}

As OB is poorly absorbed, it mainly acts at a local level, a characteristic explaining the almost absence of significant side effects.

\section{Acute toxicology}

No fatalities occurred when the drug was administered orally at doses up to $1,500 \mathrm{mg} / \mathrm{kg}$ and $1,000 \mathrm{mg} / \mathrm{kg}$ in rats and dogs, respectively.

\section{Chronic toxicity in animal models}

In animal models, OB has proven minimal toxicity, and overdose should not be a concern. In addition, no embryotoxicity, teratogenic, or mutagenic effects were observed in animal studies. Oral doses of $80 \mathrm{mg} / \mathrm{kg}$ of $\mathrm{OB}$ administered to laboratory animals for 180 days did not cause any changes in blood chemistry or histologic profiles. No embryotoxicity or teratogenic effects were observed in rats or rabbits at doses up to $60 \mathrm{mg} / \mathrm{kg}$. No mutagenic effects were observed.

\section{Chronic toxicity in humans}

In humans, OB has a placebo-like tolerability without systemic anticholinergic effects. The spasmolytic activity of the drug on the gastrointestinal tract is evident at doses that neither affect the gastric secretion nor produce atropine-like side effects. So far, almost no side effects were associated with the use of OB. In fact, two trials did not report any adverse effect. ${ }^{41,42}$ Mild nausea was reported in another study. ${ }^{36}$ Comparisons with other spasmolytic agents showed low incidence of weakness and dizziness for OB. ${ }^{38}$ Concerning dropouts, a placebo-controlled study revealed two in the OB group compared with one in the placebo group. ${ }^{34}$ Data from safety and postmarketing observation showed that $\mathrm{OB}$ is well tolerated and that side effects do not differ with those seen with placebo. In fact, after 10 years, only two adverse reactions (urticaria) have been reported. ${ }^{43}$ No drug interactions have been reported to date. OB can be given safely to patients with hepatic, renal, and cardiac disease.

\section{Conclusion}

OB possesses distinct smooth muscle favorable properties and effects on visceral perception. It shows a localized activity, as it is poorly absorbed and selectively taken up in the lower gastrointestinal tract. The drug reduces abdominal pain and discomfort in patients with IBS. The efficacy and tolerability of $\mathrm{OB}$ are better compared with both placebo and other similar drugs. Long-term treatment could be safely and effectively applied in most patients with IBS.

\section{Disclosure}

The authors report no conflicts of interest in this work. 


\section{References}

1. Scalera A, Loguercio C. Focus on irritable bowel syndrome. Eur Rev Med Pharmacol Sci. 2012;16(9):1155-1171.

2. Chang JY, Talley NJ. An update on irritable bowel syndrome: from diagnosis to emerging therapies. Curr Opin Gastroenterol. 2011;27(1): 72-78.

3. Forte E, Pizzoferrato M, Lopetuso L, Scaldaferri F. The use of antispasmodics in the treatment of irritable bowel syndrome: focus on otilonium bromide. Eur Rev Med Pharmacol Sc. 2012;16(1):25-37.

4. Lesbros-Pantoflickova D, Michetti P, Fried M, Beglinger C, Blum AL. Meta-analysis: the treatment of irritable bowel syndrome. Aliment Pharmacol Ther. 2004;20(11-12):1253-1269.

5. Clavé P, Acalovschi M, Triantafillidis JK, et al. Randomised clinical trial: otilonium bromide improves frequency of abdominal pain, severity of distention and time to relapse in patients with irritable bowel syndrome. Aliment Pharmacol Ther. 2011;34(4):432-442.

6. Bruley des Varannes S. Irritable bowel syndrome: outcome aspects. Gastroenterol Clin Biol. 2009;33 Suppl 1:S84-S90.

7. Mearin F, Baro E, Roset M, et al. Clinical patterns over time in irritable bowel syndrome: symptom instability and severity variability. Am J Gastroenterol. 2004;99(1):113-121.

8. Hahn B, Watson M, Yan S, et al. Irritable bowel syndrome symptom patterns. Frequency, duration and severity. Dig Dis Sci. 1998;43(12): 2715-2718.

9. Talley NJ, Weaver AL, Zinsmeister AR, Melton LJ. Onset and disappearance of gastrointestinal symptoms and functional gastrointestinal disorders. Am J Epidemiol. 1992;136(2):165-177.

10. Kay L, Jorgensen T, Jensen KH. The epidemiology of irritable bowel syndrome in a random population: prevalence, incidence, natural history and risk factors. J Intern Med. 1994;236(1):23-30.

11. Owens DM, Nelson DK, Talley NJ. The irritable bowel syndrome: long term prognosis and the physician-patient interaction. Ann Intern Med. 1995;122(2):107-112.

12. Guilera M, Balboa A, Mearin F. Bowel habit subtypes and temporal patterns in irritable bowel syndrome. Systematic review. Am J Gastroenterol. 2005;100(5):1174-1184.

13. Mearin F, Badía X, Balboa A, et al. Predictive factors of irritable bowel syndrome improvement: 1-year prospective evaluation in 400 patients. Aliment Pharmacol Ther. 2006;23(6):815-826.

14. El-Serag HB, Pilgrim P, Schoenfeld P. Systemic review: natural history of irritable bowel syndrome. Aliment Pharmacol Ther. 2004;19(8): 861-870.

15. Evangelista S. Benefits from long-term treatment in irritable bowel syndrome. Gastroenterol Res Pract. 2012;2012:936960.

16. Evangelista S. Quaternary ammonium derivatives as spasmolytics for irritable bowel syndrome. Curr Pharm Des. 2004;10(28):3561-3568.

17. Evangelista S, Cochet P, Bromet N, Criscuoli M, Maggi CA. A distribution study with. $1{ }^{4} \mathrm{C}$-otilonium bromide in the rat: evidence for selective tropism for large intestine after oral administration. Drug Metab Dispos. 2000;28(6):643-647.

18. Sutton JA, Kilminster SG, Mould GP. The clinical pharmacology of single doses of otilonium bromide in healthy volunteers. Eur J Clin Pharmacol. 1997;52(5):365-369.

19. Shin BS, Kim JJ, Kim J, et al. Oral bioavailability and enterohepatic recirculation of otilonium bromide in rats. Arch Pharm Res. 2008;31(1): $117-124$

20. Catalioto RM, Triolo A, Giuliani S, et al. Increased paracellular absorption by bile salts and P-glycoprotein stimulated efflux of otilonium bromide in Caco-2 cells monolayers as a model of intestinal barrier. J Pharm Sci. 2008;97(9):4087-4100.

21. Amenta F, Baroldi P, Ferrante F, et al. Autoradiographic localization of octylonium bromide binding sites in the rat gastrointestinal tract. Arch Int Pharmacodyn Ther. 1991;311:5-19.

22. Evangelista S, Giechetti A, Chapelain B, et al. Receptor binding profile of otilonium bromide. Pharmacol Research. 1998;38(2):111-117.
23. Lindqvist S, Hernon J, Sharp P, et al. The colon-selective spasmolytic otilonium bromide inhibits muscarinic $\mathrm{M}(3)$ receptor-coupled calcium signals in isolated human colonic crypts. Br J Pharmacol. 2002;137(7): 1134-1142.

24. Martínez-Cutillas M, Gil V, Gallego D, et al. Mechanisms of action of otilonium bromide in human cultured smooth muscle cells and rat colonic strips. Neurogastroenterol Motil. 2013;25(12):e803-e812.

25. Strege PR, Evangelista S, Lyford GL, Sarr MG, Farrugia G. Otilonium bromide inhibits calcium entry through L-type calcium channels in human intestinal smooth muscle. Neurogastroenterol Motil. 2004;16(2):167-173.

26. Strege PR, Sha L, Beyder A, et al. T-type $\mathrm{Ca}(2+)$ channel modulation by otilonium bromide. Am J Physiol Gastrointest Liver Physiol. 2010;298(5):G706-G713.

27. Santicioli P, Zagorodnyuk V, Renzetti AR, Maggi CA. Antimuscarinic, calcium channel blocker and tachykinin $\mathrm{NK}_{2}$ receptor antagonist actions of otilonium bromide in the circular muscle of guinea-pig colon. Naunyn Schmiedebergs Arch Pharmacol. 1999;359(5):420-427.

28. Cipriani G, Santicioli P, Evangelista S, et al. Effect of otilonium bromide and ibodutant on the internalization of the $\mathrm{NK}_{2}$ receptor in human colon. Neurogastroenterol Motil. 2011;23(1):96-102.

29. Traini C, Cipriani G, Evangelista S, et al. Chronic treatment with otilonium bromide induces changes in L-type Ca2+ channel, tachykinins, and nitric oxide synthase expression in rat colon muscle coat. Neurogastroenterol Motil. 2013;25:e728-e739.

30. Gallego D, Aulí M, Aleu J, et al. Effect of otilonium bromide on contractile patterns in the human sigmoid colon. Neurogastroenterol Motil. 2010;22(6):e180-e191.

31. Martin MT, Hove-Madsen L, Jimenez M. Otilonium bromide inhibits muscle contractions via L-type calcium channels in the rat colon. Neurogastroenterol Motil. 2004;16(2):175-183.

32. Czimmer J, Süto G, Király A, Mózsik G. Otilonium bromide enhances sensory thresholds of volume and pressure in patients with irritable bowel syndrome. J Physiol Paris. 2001;95(1-6):153-156.

33. Narducci F, Bassotti G, Granata MT, et al. Colonic motility and gastric emptying in patients with irritable bowel syndrome. Effect of pretreatment with octylonium bromide. Dig Dis Sci. 1986;31(3):241-246.

34. Battaglia G, Morselli-Labate AM, Camarri E, et al. Otilonium bromide in irritable bowel syndrome: a double-blind, placebo-controlled, 15-week study. Aliment Pharmacol Ther. 1998;12(10):1003-1010.

35. Glende M, Morselli-Labate AM, Battaglia G, Evangelista S. Extended analysis of a double-blind, placebo-controlled, 15-week study with otilonium bromide in irritable bowel syndrome. Eur J Gastroenterol Hepatol. 2002;14(12):1331-1338.

36. Baldi F, Longanesi A, Blasi A, et al. Clinical and functional evaluation of the efficacy of otilonium bromide: a multicenter study in Italy. Ital J Gastroenterol. 1991;23(8 Suppl 1):60-63.

37. Chang FY, Lu CL, Luo JC, et al. The evaluation of otilonium bromide treatment in Asian patients with irritable bowel syndrome. J Neurogastroenterol Motil. 2011;17(4):402-410.

38. Defrance P, Casini A. A comparison of the action of otilonium bromide and pinaverium bromide: study conducted under clinical control. Ital J Gastroenterol. 1991;23(8 Suppl 1):64-66.

39. Mollica G, Manno G. Otilonium bromide-diazepam in the treatment of the irritable colon. A controlled study versus otilonium bromide. Clin Ter. 1992;141(8):129-134.

40. Boeckxstaens G, Corazziari ES, Mearin F, Tack J. IBS and the role of otilonium bromide. Int J Colorectal Dis. 2013;28(3):295-304.

41. Villagrasa M, Boix J, Humbert P, Quer JC. Aleatory clinical study comparing otilonium bromide with a fiber-rich diet in the treatment of irritable bowel syndrome. Ital J Gastroenterol. 1991;23(8 Suppl 1):67-70.

42. Heading R, Bardhan K, Hollerbach S, Lanas A, FisherI G. Systematic review: the safety and tolerability of pharmacological agents for treatment of irritable bowel syndrome. A European perspective. Aliment Pharmacol Ther. 2006;24(2):207-236.

43. Spinelli A. Irritable bowel syndrome. Clin Drug Invest. 2007;27(1):15-33. 


\section{Publish your work in this journal}

Clinical and Experimental Gastroenterology is an international, peerreviewed, open access journal, publishing all aspects of gastroenterology in the clinic and laboratory, including: Pathology, pathophysiology of gastrointestinal disease; Investigation and treatment of gastointestinal disease; Pharmacology of drugs used in the alimentary tract;
Immunology/genetics/genomics related to gastrointestinal disease. This journal is indexed on CAS. The manuscript management system is completely online and includes a very quick and fair peer-review system. Visit http://www.dovepress.com/testimonials.php to read real quotes from published authors.

Submit your manuscript here: http://www.dovepress.com/clinical-and-experimental-gastroenterology-journal 